ISSN 1518-3483

Licenciado sob uma Licença Creative Commons

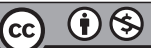

\title{
A fabricação da disciplina escolar Português ${ }^{1}$
}

\section{The fabrication of Portuguese as a school discipline}

\section{Clecio Bunzen}

Docente da Universidade Federal de São Paulo, Guarulhos, SP - Brasil, e-mail: clecio.bunzen@gmail.com

\section{Resumo}

O objetivo do presente trabalho é realizar uma breve reflexão sobre o surgimento e a ascensão da disciplina escolar Português, responsável pelo ensino formal da língua materna nas escolas. Nesse sentido, destacaremos discussões sobre a fabricação de um espaço/ tempo para que os alunos aprendam a se apropriar dos saberes escolares e metadiscursos sobre a língua escrita. Ao nos basear nos estudos sobre as disciplinas escolares, apresentamos uma interpretação sobre o surgimento da disciplina escolar Português (na escola secundária) no âmbito de uma política linguística iluminista dos séculos XVIII e XIX, que envolve aspectos dos processos de gramaticalização e escolarização da língua materna

${ }^{1}$ O presente artigo sintetiza a discussão que realizamos no primeiro capítulo da tese "Dinâmicas discursivas na aula de Português: os usos do livro didático e projetos didáticos autorais" (BUNZEN, 2009). 
como um projeto imprescindível de identidade nacional. Em seguida, destacaremos alguns aspectos que reconfiguram a disciplina Português no século $X X$, com destaque para a construção dos programas oficiais e para a relação entre os estudos acadêmicos sobre o ensino de língua materna e as políticas públicas (PCN, PNLD, PNBE, etc.).

Palavras-chave: História das disciplinas escolares. Língua materna. Política linguística.

\section{Abstract}

This paper aims at discussing the emergence and rise of Portuguese as a school discipline responsible for formal teaching of language of the Brazilian national language in its education system. It seeks to gather ideas about the social construction of this school discipline and its legimacy by the prescriptive curriculum. The article also emphasizes discussions on how schools offer both space and time to students so that they could master school abilities and metadiscourses about written language. Based on studies of the history of school disciplines, we offer an interpretation of the emergence of Portuguese as a school subject in the context of an Enlightenment language policy of the Eighteenth and Nineteenth centuries, which involves aspects of two processes: grammaticalization and institutionalization in the school system of national languages as an essential project of national identity. We conclude the paper by discussing the construction of public programs, academic studies on mother tongues' teaching and public policies.

Keywords: : History of school disciplines. Mother tongue. Linguistic policy.

\section{Introdução}

Definir o que é uma aula de Português ou de língua materna, enquanto disciplina escolar², não é tarefa fácil. Professores em serviço,

2 Compreendemos aqui a disciplina escolar como parte integrante da cultura escolar (CHERVEL, 1990), ou seja, como um espaço-tempo criado no interior de disputas entre diversos conhecimentos e formas de organização dos saberes para compor o currículo escolar.

Rev. Diálogo Educ., Curitiba, v. 11, n. 34, p. 885-911, set./dez. 2011 
ex-professores, estudantes, pais, professores das aulas televisivas, pedagogos, linguistas, linguistas aplicados, autores de livros didáticos, editores e jornalistas darão respostas diversas e destacarão facetas de diferentes objetos de ensino. Percebe-se, então, que historicamente são (re)construídas representações sobre práticas escolares e sua inter-relação com a disciplina de Português nas aulas, nos livros escolares, nos documentos oficiais e nos textos acadêmicos. Algumas dessas representações são mais legitimadas do que outras, ultrapassando os muros das escolas para serem ressignificadas em programas televisivos, em revistas para crianças e jovens, nos concursos públicos, etc.

Se pensarmos especificamente na língua materna como objeto de conhecimento, a escola torna-se uma das principais responsáveis pela (re)construção de saberes sobre a língua como objeto de contemplação e apreciação. Por essa razão, em todas as situações que mencionamos anteriormente, as diversas facetas das práticas escolares e dos objetos de ensino emergem, integradas/imbricadas a construções identitárias do próprio professor de língua materna. Por isso, como bem disse Batista (1997, p. 3), “aquilo que se ensina não são as próprias coisas (a língua ou a história mesma), mas, antes, um conjunto de conhecimentos sobre as coisas ou um modo, dentre outros possíveis, de se relacionar com elas". $\mathrm{Na}$ arena curricular há de fato "verdadeiras lutas" e "polêmicas" do ponto de vista político, econômico, científico e escolar em relação ao funcionamento, à seleção e à representação dos objetos e objetivos de ensino na constituição dessa disciplina escolar denominada historicamente por "Gramática Nacional, Língua Pátria, Idioma Nacional, Comunicação e Expressão, Português” (BATISTA, 1997, p. 3).

Ao assumir essa perspectiva histórica, o objetivo do presente trabalho é refletir sobre determinadas facetas, levando em consideração que as práticas escolares encontram-se historicamente marcadas por movimentos de permanência, rupturas, deslocamentos, sedimentação, tensão e escolhas curriculares. Assim como pesquisas anteriores (LAURIA, 2004; RAZZINI, 2000; SOARES, 2002), nos concentraremos no currículo prescrito, com destaque para as leis, programas escolares, propostas 
curriculares e livros didáticos da disciplina. Por isso, procuramos interpretar a fabricação de um espaço/tempo (cronotopo) que tem permitido crianças e jovens aprenderem e se apropriarem dos saberes escolares sobre a língua(gem) escrita, com destaque para a língua (nacional e/ou materna). Nos próximos itens, voltamos nossa atenção justamente para alguns aspectos históricos das práticas curriculares prescritas em documentos que se encontram, de alguma forma, inter-relacionadas com o ensino formal de língua, com fortes implicações na seleção de saberes a serem escolarizados. Almejamos, assim, apresentar uma interpretação do próprio surgimento da disciplina escolar Português e discutir práticas e ações que acompanham os agentes responsáveis pelo ensino formal da língua no ensino secundário (atual ensino fundamental II), com destaque para três aspectos inter-relacionados e apontados por Chervel (1990): a gênese da disciplina escolar, seus objetivos e seu funcionamento.

\section{Ausência do vernáculo nas escolas e a ênfase nas línguas clássicas}

No início do século XVI, a educação encontrava-se calcada na tradição oral e ligada às necessidades de cada grupo: aprendia-se por meio da observação e do trabalho coletivo. Após o "descobrimento", esse contexto de educação não formal começa a se modificar, pois algumas crianças indígenas e alguns filhos dos homens da elite começam a conviver com um processo inicial de educação formal. Algumas crianças indígenas e mamelucos, para transformarem-se em "um povo agradável a Cristo", nas palavras do padre José de Anchieta, frequentavam três ou quatro horas na "escola" para aprender: as doutrinas religiosas, o disciplinamento do corpo e os três elementos básicos: ler, escrever e contar. No entanto, conforme Hilsdorf (2005), somente depois de falar o português e conhecer os fundamentos da doutrina cristã é que eles iniciariam a "escola de ler e escrever".

A educação jesuítica foi bastante intensa entre 1549-1570, uma vez que as ideias pedagógicas do Padre Manuel da Nóbrega - compatíveis 
com o ideal colonizador e mercantilista - apostavam em formar um número maior adeptos do catolicismo na colônia. Para atingir tal objetivo, o ensino oral do português europeu tornou-se necessário; assim como os evangelizadores tiveram que aprender as línguas indígenas pelo convívio e contato com os índios ${ }^{3}$. No entanto, após a morte do Padre Manuel da Nóbrega em 1570, diminui-se consideravelmente o ensino das primeiras letras e do catecismo elementar nas aldeias jesuítas.

O aprendizado oral do português europeu defendido por Nóbrega e relacionado com a catequização dos curumins foi praticamente excluído do currículo. Em seu lugar, surgem as práticas pedagógicas baseadas na Ratio Ataque Instituto Studiorum Societas Jesu (1599), ou seja, um currículo inspirado numa visão retórico-gramatical da cultura humanística. Neste contexto, em que o português europeu não era a língua falada no cotidiano de todas as capitanias, o currículo voltava-se para a gramática e literatura das línguas clássicas.

Nota-se que a presença greco-romana é evidente, uma vez que a Ratio Studiorum tinha como um dos principais objetivos o bom conhecimento dos clássicos e o uso correto das línguas latinas e gregas, com nenhum espaço dedicado a metadiscursos sobre a língua materna ou oficial/ nacional. Os alunos do ensino secundário liam textos clássicos em latim e grego: cartas de Cícero; poesias de Virgílio, Catulo e Ovídio; diálogos de Luciano. Exigia-se, por exemplo, que o professor falasse sempre em latim e os exercícios escolares também tinham que ser escritos na língua do Lácio, representante oficial da classe dominante e do clero. Como bem explica Auroux (1992, p. 46),

as crianças gregas ou latinas que frequentavam a escola do gramático já sabiam sua língua, sendo a gramática só uma etapa do acesso à cultura escrita. Para um europeu do século IX, o latim é antes de tudo uma segunda língua que ele deve aprender. A gramática latina

\footnotetext{
${ }^{3}$ Vale salientar aqui que a lusitanização nas costas da África, na Índia e no continente Sul-Americano, nas palavras de llari e Basso (2006, p. 39), "resultou em impor o português como língua da administração e do ensino, enquanto boa parte da população continuou falando as línguas nativas".
} 
existe e vai se tornar prioritariamente uma técnica de aprendizagem da língua [...]. Foi necessário primeiro que a gramática de uma língua já gramaticalizada fosse massivamente empregada para fins de pedagogia linguística, porque esta língua se tornou progressivamente uma segunda língua, para que a gramática se tornasse - o que tomará um tempo considerável - uma técnica geral de aprendizagem, aplicável a toda língua, aí compreendida a língua materna.

Os colégios fundados pelos jesuítas no Brasil ministravam disciplinas com caráter predominantemente literário e retórico, com destaque para as chamadas "línguas clássicas". As línguas vernáculas não tinham espaço nos colégios, por isso o latim (uma língua estrangeira) era utilizado como uma das línguas preferenciais para o conhecimento do alfabeto e dos princípios básicos da decifração (leitura silenciosa e em voz alta). Além disso, não podemos esquecer de que havia de fato uma supremacia do latim sobre a língua vernácula, uma vez que, até o fim da Idade Média, o latim era a língua utilizada para escrever na Europa. Soares (2002) atribui essa situação a diversos fatores, a saber: (i) o público que passava por um processo de escolarização tinha interesse em seguir o modelo educacional que tinha como base o latim; (ii) a língua portuguesa europeia não era a língua falada em grande parte das interações orais e escritas neste período ${ }^{4}$. Essa situação só será alterada com a implementação de políticas que defendiam o papel das o papel das línguas nacionais no processo de escolarização no Ocidente.

\section{Língua nacional e o processo de gramaticalização ${ }^{5}$ da língua portuguesa}

No cenário europeu, entre os séculos XVII e XVIII, as línguas dos Estados-nação adquiriram maior status na constituição dos saberes

\footnotetext{
${ }^{4}$ A título de exemplificação podemos citar a criação de línguas gerais que mostra relações híbridas entre o português e as línguas indígenas (ILARI; BASSO, 2006).

${ }^{5}$ Entendido aqui como processo sócio-histórico que se caracteriza pelo desenvolvimento de duas tecnologias: a gramática e o dicionário (AUROUX, 1992).
} 
escolares. Comenius, por exemplo, apresentou preocupações com a didática das línguas, enquanto que os oratorianos e os mestres de Port-Royal ensinavam a partir da língua do Estado, consolidando a criação de gramáticas nacionais (AUROUX, 1992). Em Portugal, algumas gramáticas também davam sinais de um ensino simultâneo do latim com o português europeu. Casagrande e Bastos (2002), ao fazerem uma análise do ensino de língua e das políticas linguísticas nos séculos XVI e XVII, mostram que Amaro de Reboredo, autor de Methodo grammatical para todas as línguas, de 1969, defendia a importância do ensino de português nas escolas e da criação de uma disciplina escolar para o vernáculo no ensino superior. No entanto, são as reformas pombalinas, fortemente influenciadas pelo Iluminismo europeu e pelo Racionalismo moderno, que acabam legitimando tal posicionamento, uma vez que se tornou necessário, para uma política mercantil e absolutista, maior divulgação/implementação da "língua do Príncipe" nas terras "conquistadas".

Com a necessidade política de ensinar a língua da metrópole para preservá-la e passá-la aos povos dominados ${ }^{6}$, a reforma pombalina consolidou uma política de expansão linguística de uso interno e externo, pois, do ponto de vista político, foi a maior responsável pelo ensino obrigatório da língua portuguesa em Portugal e no Brasil. Como bem diz Auroux (1992, p. 49),

a velha correspondência uma língua, uma nação, tomando valor não mais pelo passado mas pelo futuro, adquire um novo sentido: as nações transformadas, quando puderam, em Estados, estes vão fazer da aprendizagem e do uso de uma língua oficial uma obrigação para os cidadãos.

${ }^{6}$ Vejamos o que nos diz o Alvará de D. José I de 1759: "conformando-me Eu como o exemplo desta e de outras nações iluminadas, e desejando, quanto a Mim, adiantar a cultura da língua Portuguesa nestes Meus Reinos e Domínios, para que neles possa haver vassalos úteis ao Estado, Sou servido ordenar que os mestres da língua latina, quando receberem nas suas classes os discípulos, para Ihes ensinarem, os instruam previamente, por tempo de seis meses, se tantos forem necessários para a instrução dos alunos, na Gramática Portuguesa composta por António José dos Reis Lobato [...]" (ANDRADE apud BOTO, 2004, p. 170). 
Nota-se, no entanto, que o Marquês de Pombal, antes mesmo da expulsão dos jesuítas, já obrigava os colonos, com a carta régia de 12 de setembro de 1757, a ensinar aos povos indígenas a língua portuguesa europeia, além de proibir o uso de línguas indígenas na colônia. Tal política linguística, conforme os comentários de Bagno (2002), tinha como objetivo impedir a prática pedagógica jesuítica de utilizar a "língua geral, de base tupi", para catequizar os índios brasileiros. Por essa razão, alguns autores defendem que essa carta de 1757 marcaria o nascimento oficial da língua portuguesa no Brasil, além da oficialização da língua portuguesa para o reino de Portugal.

Se a instrução pública tem um papel central na construção de um Estado progressista que se utiliza da língua ensinada na escola como forma de construir uma identidade nacional e metadiscursos sobre a língua nacional-oficial, o processo de gramaticalização associado à noção de progresso e nacionalidade será um aspecto central para fabricação de uma disciplina escolar que se volte para o vernáculo. Por tal razão, Luiz Antonio Verney, por exemplo, em O verdadeiro método de estudar, defendia o ensino do português europeu nas escolas, impulsionando colégios em Portugal a darem primazia ao estudo da língua nacional sobre o latim (PFROMM NETO; et al.,1974).

No contexto brasileiro, a língua portuguesa começa, então, a ser utilizada nas disciplinas de Gramática, Retórica e Poética do secundário durante a segunda metade do século XVIII, disputando um espaço com o latim, que era a língua privilegiada no currículo medieval e jesuítico ${ }^{7}$. Por essa razão, como defende Soares (2002), o ensino do vernáculo, em um primeiro momento, seguiu a tradição do latim, mas com enfoque na gramática do português. O sistema escolar inicia um processo em que ler

\footnotetext{
7 Vale lembrar aqui que o latim perdera, nos séculos XVII e XVIII, sua importância como forma de interação das pessoas cultas no cenário europeu. Segundo Pfromm Neto et al. (1974), por exemplo, eram poucas as impressões de livros escritos em latim (apenas $4 \%$ no fim do século XVIII). Esse fator parece ter favorecido, na Europa e posteriormente em suas colônias, o fortalecimento de uma língua e literatura nacionais. No Brasil, sabe-se que até os anos 60 os alunos no ginásio e no clássico continuavam tendo aulas de latim.
}

Rev. Diálogo Educ., Curitiba, v. 11, n. 34, p. 885-911, set./dez. 2011 
e escrever em português, assim como estudar a gramática portuguesa, passam a ser "componentes curriculares" (SOARES, 2002) que disputarão espaço com as práticas do currículo humanista clássico nos séculos seguintes.

Do ponto de vista de uma política linguística pós-independência, uma decisão política no parlamento determinou que o ensino da língua deveria se dar através do uso da gramática da "língua nacional", utilizando-se essa categorização "como uma forma de não nomear a língua da nova Nação pelo nome do antigo colonizador" (GUIMARÃES, 2005, p. 15). Nesse contexto político, a "língua nacional" passou a ser um dos saberes escolares necessários para a formação dos setores burocráticos e intelectuais da nova "nação". No ensino secundário, a língua portuguesa e sua literatura foram sendo lentamente incluídas no currículo oficial.

\section{Português: uma "nova" disciplina curricular e institucional}

Razzini (2000), no seu estudo sobre os regulamentos que prescreviam o currículo no Colégio Pedro II no Rio de Janeiro, faz importantes esclarecimentos sobre o ensino de língua materna no nível secundário nos séculos XIX e XX. Um dos fatores ressaltados pela autora é que o ensino do vernáculo continuou durante quase todo o século XIX ainda dependente do ensino do latim. Assim, a língua portuguesa era analisada nas disciplinas Gramática Geral e/ou Gramática Filosófica, as quais priorizavam comparações entre o vernáculo e o latim, no primeiro ano do curso secundário ${ }^{8}$. Segundo Pfromm Neto et al. (1974) foi somente em 1838 que a "língua nacional" apareceu como objeto de ensino principal das

\footnotetext{
${ }^{8}$ Em 1841, por exemplo, as disciplinas de Gramática Geral e Gramática Nacional só aparecem no 10 ano com cinco lições semanais, diferentemente do latim, que era ensinado durante os sete anos do secundário. O professor de Latim era o mesmo que lecionava a disciplina de Gramática Nacional, enfatizando como objeto de ensino a estrutura gramatical da língua portuguesa nos níveis morfológico e sintático.
} 
aulas de Gramática Nacional. Por isso, é possível afirmar que os conhecimentos gramaticais foram, em certo sentido, essenciais para os processos de emergência e de institucionalização do vernáculo enquanto disciplina escolar, uma vez que "a gramática foi um vetor fundamental de estruturação disciplinar” (DIONÍSIO, 2000, p. 55).

A partir da reforma de Couto Ferraz, em 1854, segundo Razzini (2000), percebe-se uma significativa ampliação no desenvolvimento do ensino do vernáculo, com a criação de duas disciplinas escolares para o $1^{\circ}$ ano do secundário no Colégio Pedro II: Leitura e Recitação de Português e Exercícios Ortográficos. A primeira disciplina mostra-nos que os textos em língua estrangeira passam a dar espaço para os autores portugueses e brasileiros, enquanto a segunda define a ortografia como objeto de ensino em um período em que ainda não existiam acordos ortográficos para regulamentar sobre as formas de grafar as palavras. Essa reforma, segundo a autora, marca uma "ascensão do estudo da língua portuguesa e de sua literatura, a qual passou a servir de exemplo do bem falar e do bem escrever/compor em vernáculo, predicados indispensáveis para aqueles que se destinavam às carreiras públicas e às profissões liberais" (RAZZINI, 2000, p. 43).

Com as novas reformas implementadas no Pedro II em 1862, as três disciplinas voltadas para o estudo do idioma nacional foram agrupadas sob denominação de "Português" apenas no $1^{\circ}$ ano. No entanto, até o fim do período imperial, vamos assistir a uma ampliação da disciplina causada por alguns fatores, a saber: (i) a sua inclusão nos chamados "exames preparatórios" e (ii) a criação do cargo de professor de Português em 23 de agosto de 1871 (PFROMM NETO et al., 1974). Depois disso, o Decreto 4.430, de 30 de outubro de 1869, começou a exigir, após 1871, o exame obrigatório da língua portuguesa para admissão nos cursos superiores do Império, diferentemente do que ocorria no início do século XIX, cujos exames para cursos jurídicos, por exemplo, eram de gramática latina e um língua estrangeira (francês ou inglês, por exemplo).

O ensino do Português nos três anos iniciais do secundário possibilitou, conforme as análises de Haidar (1972) e de Razzini (2000): (i) a entrada de atividades de escrita (composição), antes presentes apenas nas 
séries finais do secundário; (ii) enfoque na chamada gramática histórica e no processo de formação do português; (iii) a migração de elementos da disciplina de Gramática Filosófica como análises "lógica [sintática] e gramatical [morfológica]". Ao mesmo tempo, permaneceram as práticas de leitura e recitação dos clássicos e exercícios ortográficos com um enfoque didático baseado em exemplos, além dos clássicos como objeto de contemplação para aulas de leitura e escritura (RAZZINI, 2000).

Em 1878, o ensino do vernáculo volta a ser objeto de discussão, uma vez que um dos aspectos da reforma de Leôncio de Carvalho era a transferência das aulas de Português dos $1^{\circ}$ e $2^{\circ}$ anos do secundário para o ensino primário. Em um curto período, a disciplina de Português ficou apenas no sétimo ano do secundário, contemplando assim "gramática filosófica, análises e exercícios de redação verbal e escrita” (RAZZINI, 2000, p. 71). No entanto, segundo a autora, essa reforma não se concretizou de fato, uma vez que o ensino do vernáculo incorporou outros aspectos das aulas de Retórica e Poética, avançando ainda mais nas décadas seguintes.

No início da década de 80 do século XIX, por exemplo, a disciplina, antes ameaçada de redução, passara a fazer parte da grade curricular das cinco séries iniciais do ensino secundário, com um aumento considerável no ensino da escrita. O ensino propedêutico também impulsionou um maior crescimento da disciplina no fim do Império, uma vez que os exames passaram a exigir cada vez mais conhecimentos escolares específicos sobre o vernáculo. O exame de Português, por exemplo, passou a anteceder ao das outras disciplinas escolares. Outra consequência visível é o aumento de exercícios escritos nos dois primeiros anos do secundário, provavelmente em função da "ampliação da prova escrita de português nos exames preparatórios de 1891” (RAZZINI, 2000, p. 90). No fim do século XIX e início do século XX, as reformas ocorridas apontam justamente para a permanência do ensino de Português nas quatro séries iniciais do secundário com uma carga horária de dez aulas semanais. Assim, antes mesmo da emergência do nacionalismo republicano, houve a ascensão do Português como disciplina escolar no currículo da escola secundária brasileira. 


\section{Programas oficiais e ensino do Português: os efeitos do currículo prescrito}

A fundação do Ministério da Educação e da Saúde Pública na década de 30 vem consolidar, do ponto de vista das políticas públicas e das políticas de governo, alterações entre os programas oficiais e as disciplinas escolares. Nesse sentido, programas oficiais e disciplinas específicas para cada série do secundário aparecem no decreto 19.890 de 1931, documento responsável também pela equiparação de todos os colégios secundários ao Colégio Pedro II, pela seriação ${ }^{9}$ e frequência obrigatória para ingresso nas faculdades (RAZZINI, 2000). Em junho de 1931, a disciplina passa a ser denominada de Português, com objetivos e conteúdos fixados pelas instruções metodológicas para cada disciplina. O objetivo geral da disciplina era representado da seguinte forma pela nova regulamentação:

proporcionar ao estudante a aquisição efetiva da língua portuguesa, habilitando-o a exprimir-se corretamente, comunicando-lhe o gosto da leitura dos bons escritores e ministrando-lhes o cabedal indispensável à formação do seu espírito bem como à sua educação literária (BRASIL, 1931 apud ZILBERMAN, 1996, p. 21).

Para atingir tais objetivos, a disciplina de Português deveria trabalhar a leitura de textos literários, pois eles "disciplinam a inteligência" e ajudam/previnem os alunos das possíveis dificuldades de redação. Os textos eram "cuidadosamente escolhidos" para que os alunos realizassem atividades com o vocabulário, ortografia e fatos gramaticais, partindo das "observações feitas pelos alunos". Nas duas primeiras séries do curso fundamental, com quatro horas/aulas semanais de 50 minutos, privilegiavam-se no programa oficial de 1931: (i) "o ensinamento oral, tendo como base a reprodução e a composição orais, a recitação de poesias, a leitura e o estudo de gramática somente quando este se fizesse necessário

\footnotetext{
${ }^{9}$ A partir deste decreto, o ensino secundário passou a ser chamado de: fundamental (com duração de cinco anos) e complementar (com a duração de dois anos) para candidatos aos cursos superiores.
} 
ou algum educando questionasse" (FACCINA, 2000, p. 11); (ii) "leitura de trechos de pensadores e poetas contemporâneos, escolhidos de acordo com a capacidade média da classe. Explicação dos textos. Estudo metódico do vocabulário. Reprodução oral do assunto lido. Recitação de pequenas poesias, previamente interpretadas. Composição oral [...]" (ZILBERMAN, 1996, p. 23).

A década de 40 do século XX é marcada pelo movimento de afirmação de um ensino de língua materna voltado para um sentimento nacionalista, intensificando o trabalho com a língua literária e o respeito pelo patrimônio nacional em contraposição às ameaças estrangeiras ${ }^{10}$. A análise de Zilberman (1996) de três livros de leitura, publicados entre 1930 e 1950, demonstrou o papel do texto literário na construção de um corpus textual que veicula valores e constrói um "cânone" da literatura e língua nacional. A leitura escolar, segundo as prescrições das Instruções Metodológicas de 1942, devia voltar-se para a formação de uma "consciência patriótica" e "humanística" por meio de textos literários importantes para a formação de uma "personalidade integral" dos alunos.

As pesquisas sobre livro didático de Português indicam que, a cada novo programa e reforma de ensino, os autores e editores procuravam atender às alterações e sugestões de conteúdos e metodologias. Por essa razão, era comum encontrar, nos próprios livros, as "Instruções Pedagógicas para a execução do programa de Português". Zilberman (1996), como base na análise de trechos do programa de 1942, presente no livro de José Marques da Cruz - Seleta: português prático para o $1^{a}$ e $2^{a}$ série do curso secundário - explica que o ensino de Português se configura por meio de três componentes: gramática para que o aluno possa se "exprimir corretamente", leitura explicada de "bons escritores" e outros exercícios.

Recomendava-se, então, a leitura de escritores nacionais e estrangeiros (Cervantes, Goethe, Gil Vicente, Dante, etc.) e temas específicos

10 Segundo Faraco (2007, p. 47), no Estado Novo getulista, "buscou-se silenciar o uso público das línguas de imigração e cultivou-se a ideia de se padronizar a pronúncia do país". 
para cada série. A família, a escola e a terra natal, por exemplo, são temas que devem ser tratados na $1^{\mathrm{a}}$ série ginasial, enquanto que a paisagem e a vida em cada uma das regiões naturais do Brasil são temáticas da $2^{\mathrm{a}}$ série. Essa questão é de extrema importância para percepção de fabricação da disciplina, pois entram em jogo os "temas" possíveis de serem abordados no trabalho com língua materna. Temos aqui indícios de como a disciplina escolar começa a imbricar objetos de ensino fixos pela tradição escolar como a literatura e a gramática com a organização de uma pedagogia da exploração temática. Lauria (2004), ao analisar a coleção seriada Curso da língua pátria (1944), demonstra como os textos da antologia procuravam atender às diretrizes da Reforma Capanema de 1942, pois traziam textos literários (poemas, trechos de romances, fragmentos de contos) normalmente voltados para alguns dos temas exigidos pela reforma. A qualidade da mulher como "rainha do lar", por exemplo, era ressaltada nos textos, assim como a pátria, as paisagens e personagens brasileiros.

A disciplina de Português apresenta uma reconfiguração com movimentos de permanências e rupturas de objetos de ensino e aspectos metodológicos com os programas de Português de 1942 e 1951, capazes de alterar algumas características das aulas de Português e os perfis dos livros didáticos. Em primeiro lugar, é visível que os textos são selecionados com base nas temáticas exigidas pelos programas para as séries iniciais do ginásio: textos em prosa e em verso de autores do século XVIII e XIX, com destaque para cinco temas: terra natal, escola, família, exemplos de feitos heroicos e virtudes cívicas (LAURIA, 2004). Em segundo lugar, a programação oficial de 1951 prescrevia que as aulas deveriam ter interpretação de textos de leitura, exercícios de linguagem oral, questões gramaticais, vocabulário e redação. Como aponta Fregonezi (1999, p. 17), "ao lado do roteiro de sugestões para as aulas de leitura, atividades de redação e procedimentos metodológicos para aulas de vocabulário e de linguagem oral, são também comuns as listas de conteúdo programático a serem desenvolvidas em cada série". No geral, percebe-se que o Programa de Português de 1951 priorizava exercícios práticos de gramática e textos literários, atendendo a dois objetivos: "a habilitação do aluno para falar e 
escrever corretamente" e "a missão do professor de despertar no aluno o amor pela língua pátria e o gosto literário".

\section{Descentralização e flexibilidade para a construção curricular}

Os anos 60 são fortemente marcados pelo processo de descentralização das questões educacionais mais gerais, uma vez que a Lei de Diretrizes e Bases (LDB) de 1961 apostou no federalismo e na autonomia dos Estados na definição de sua política educacional. Do ponto de vista do currículo prescrito, assistiu-se a uma maior flexibilidade, pois, diferentemente dos anos anteriores, houve uma maior abertura para construção do currículo pelos Estados, pelos professores e pelos próprios autores-editores de livros didáticos. A LDB-61 apontava, por exemplo, algumas indicações para o ensino de cada disciplina escolar que poderia ser desenvolvida e ampliada pelos programas estaduais.

Desde a Lei n. 4024 de 61, diminuiu-se consideravelmente o caráter rígido dos programas para o ensino de Português, uma disciplina obrigatória para todas as séries do ginásio e do colegial. Apesar disso, instruções, intituladas "Amplitude e desenvolvimento do Programa de Português”, foram publicadas pelo Conselho Federal de Educação e serviram de orientação curricular no período. No livro Português no Ginásio (1965), de Raul Moreira Léllis, as recomendações apareciam explicitamente, apontando para três grandes eixos de ensino: Expressão Oral, Expressão Escrita e Gramática Expositiva.

Conforme os estudos de Fregonezzi (1999), Razzini (2000) e Lauria (2004), a Expressão Oral, nas primeiras séries ginasiais, consistia no trabalho com a leitura de textos "simples, em prosa e verso, descritivos e narrativos, com real valor literário de autores brasileiros dos últimos séculos" - informação bem próxima das recomendações de 1951, mas sem a pretensão de indicar as temáticas a serem exploradas com os textos literários. Segundo Lauria (2004), a leitura expressiva dos textos e sua "exposição oral resumida" faziam parte das práticas desse primeiro eixo. 
A Expressão Escrita priorizava a liberdade de expressão individual e visava a alcançar, através da produção de frases e redações, "uma expressão clara do pensamento" ${ }^{11}$. Para o tratamento da Gramática Expositiva, sugeria-se "um ensino acentuadamente prático e derivado de exemplos concretos. O ensino da gramática fluirá, tanto quanto possível, dos textos. Da oração se partirá para o estudo das classes de palavras".

Para adequar o sistema educacional ao modelo de desenvolvimento econômico sustentado pelo regime militar desde 1964, criaram-se algumas medidas para reformulação do ensino primário e secundário. Por meio da Lei n. 5.692, de 1971, o Governo Militar suspende a inspiração liberalista de 1961 e, baseando-se em uma tendência tecnicista, voltada para o mundo do trabalho e para o combate ao analfabetismo, amplia a obrigatoriedade escolar para oito anos: o chamado $1^{\text {a }}$ grau obrigatório e gratuito. Entre a ruptura e a continuidade com a Lei 4.024/61, os estabelecimentos de ensino passam a ser responsáveis pelo número de aulas semanais e a construir grades curriculares com um núcleo comum, global, com as peculiaridades locais, sempre visando à qualificação/formação para o trabalho desde a $5^{\mathrm{a}}$ série.

A proposta de formar trabalhadores, em plena época de ditadura militar, fazia crescer um ensino técnico em detrimento da construção de um currículo humanista clássico voltado para o ensino superior, assim "todos os cursos de $2^{\circ}$ grau deveriam ter um caráter profissionalizante”. Essa visão tecnicista incentivou também mudanças na própria concepção das disciplinas escolares e na forma de organização: optou-se por quebrar a relação histórica entre ciências e humanidades para dar visibilidade a uma proposta que continha uma relação entre três grandes áreas de estudos que deveriam se inter-relacionar: comunicação $e$ expressão, estudos sociais e ciências. Em relação à língua materna, o parecer afirma que

${ }^{11}$ Razzini (2000) vê como uma das novidades do período o estímulo à criatividade do aluno no "ensino" de redação. Na realidade, a temática do texto propiciava ao aluno um "estímulo" para escrever, diferentemente das prescrições anteriores. 
esta deverá ser encarada como instrumento por excelência de comunicação no duplo sentido de transmissão e compreensão de ideias, fatos e sentimentos e sob a dupla forma oral e gráfica, o que vale dizer: leitura, escrita e comunicação oral (BRASIL, 1971, p. 178).

A comunicação oral é considerada o elemento o de integração principal entre a língua e os estudos sociais, encarados como um mecanismo de integração do educando ao meio. Também ressalta que o ensino da língua portuguesa não deverá prescindir do seu sentido de "expressão da Cultura Brasileira”, não esquecendo das raízes que deram origem à literatura brasileira (ZOTTI, 2004, p. 177).

Nesse sentido, definem-se em 1971 as disciplinas obrigatórias, mas não há instruções metodológicas determinadas para cada disciplina, uma vez que cabe aos professores e diretores da escola a construção dos programas para cada série (desde 1962, parecer n. 77, aprovado em 15/06), com um movimento de descentralização para elaboração de propostas pelos próprios Estados e municípios. Ou seja, a flexibilidade e a aposta na variedade de currículos parecem ser características da lei, mesmo que gerem, em um período de vigilância, um conjunto de incoerências e contradições. Pela proposta, o ensino do vernáculo assume um caráter instrumental, pois deve auxiliar ao desenvolvimento de uma integração vertical com outras áreas de estudo e disciplinas. Os meios de comunicação em massa, por exemplo, eram legitimados para fazer um trabalho com as mais diversas questões. Como diz a própria lei: os estabelecimentos de ensino deverão aproveitar-se dos meios de comunicação para atingir grandes massas estudantis. Não é à toa que a disciplina Português passou a se chamar nesse período de Comunicação \& Expressão (no $1^{\circ}$ grau menor) e Comunicação em Língua Portuguesa (no $1^{\circ}$ grau maior).

Para alguns pesquisadores, o termo "comunicação" marca uma influência da concepção de língua(gem) como uma forma de comunicação humana e não mais apenas de expressão estética. Soares (2002) mostra que o que estava em jogo era a concepção de que o aluno deveria emitir e receber mensagens verbais e não verbais, minimizando o enfoque do 
ensino no saber sobre a língua. Se a ênfase é no processo de comunicação e expressão, valoriza-se a comunicação oral em seus usos mais cotidianos e a leitura como interpretação dos textos verbais e não verbais, diversificando certamente os textos que podem circular na esfera escolar e as metodologias de ensino.

Por outro lado, a transição dos anos 70 para os anos 80 foi marcada certamente por um conjunto de denúncias contra o ensino de Português das escolas públicas brasileiras. Se a escola pública não conseguia ensinar a ler e a escrever, o ensino de língua materna encontrava-se em crise. Ao lado da "crise da leitura e da escrita" e da "luta" por uma maior democratização do ensino, emerge fortemente no Brasil o "discurso da mudança” (PIETRI, 2003) que constrói discursivamente o chamado "ensino tradicional de português" (ANGELO, 2005). Por tal razão, ampliaram-se consideravelmente as pesquisas sobre o ensino - desde a alfabetização até as redações dos vestibulandos - com um impacto inicial nas propostas curriculares estaduais dos anos 70 e 80 (GERALDI; SILVA; FIAD, 1996; MARINHO, 1998).

Os textos de divulgação, pesquisas sobre o ensino e a criação de propostas curriculares estaduais, entre os anos 70 e 80 , mostram que coube aos pesquisadores universitários propor uma reflexão crítica das práticas escolares descritas anteriormente. Esses textos-documentos como os Guias curriculares para o ensino de $1^{\circ}$ grau do estado de São Paulo (1975) ou a coletânea O texto na sala de aula, organizada por Geraldi (1984) - fazem parte de um conjunto mais amplo de projetos voltados para a reformulação do ensino de língua materna. Congressos (como o COLE $^{12}$, criado em 1978), fóruns de discussão e revistas voltadas para o professor são outros exemplos de ações que (in)diretamente mostram o diálogo entre políticas públicas e científicas para a formação de professores e (re)construção de propostas curriculares. De fato, as pesquisas sobre a língua(gem) chegam, cada vez mais, ao campo de ensino de língua materna, fazendo com que os textos acadêmicos, ao lado das leis,

12 Congresso de Leitura do Brasil. 
diretrizes e dos livros didáticos, constituam uma faceta da própria história da disciplina escolar.

No confronto entre as práticas escolares vistas como "tradicionais" e as pesquisas acadêmicas, a disciplina Comunicação em Língua Portuguesa é reconfigurada pelo discurso da mudança com uma identidade escolar voltada para determinados procedimentos (leitura, produção, análise linguística), mais do que em conteúdos específicos (ROJO; CORDEIRO, 2004; ROJO, 2008). Vários documentos oficiais, como mostram as análises de Geraldi, Silva e Fiad (1996), respondem aos questionamentos da academia priorizando no discurso oficial uma concepção sociointeracionista de língua(gem), atrelada a um noção do texto como ponto de partida para o trabalho na escola, especialmente nas práticas de leitura, produção de texto e análise linguística. Além disso, a discussão do (não) ensino da gramática e do tratamento da variação linguística fecha o círculo de propostas de mudança em contraposição sempre a algo chamado de "ensino tradicional".

As sete pragas descritas por Faraco (1984) para o ensino de Português encontram-se justamente relacionadas: a escolarização dos textos, as redações, ao estudo da teoria gramatical, a organização/planejamento dos programas da disciplina que estudam "coisas inúteis", as estratégias didáticas inadequadas, etc. Esses textos-documentos partem normalmente do argumento de que

falta cientificidade na base do ensino de língua, que tem como alicerce a gramática normativa tradicional, um saber não científico - o ensino de atividades metalingüísticas que se torna um fim em si mesmo, deixando de lado o ensino propriamente da língua, a presença de um modelo de língua distanciado da realidade do aluno calcado na modalidade escrita literária de tempos atrás (ANGELO, 2005, p. 113).

O fim dos anos 80 encontra-se então marcado pela crítica acadêmica às propostas dos livros didáticos de língua materna, pela expansão das propostas curriculares estaduais para o ensino de Português e pelas discussões impulsionadas pelo Decreto Presidencial n. 91.372, de 1986, 
que: (i) estabelece Diretrizes que promovem o aperfeiçoamento do ensino/ aprendizagem da língua portuguesa, sugerindo mudanças nas práticas curriculares e na política de ensino de língua; (ii) recupera a denominação Português e não mais Comunicação \& Expressão em Língua Portuguesa.

Aumenta-se também, parece-nos, a flexibilidade do currículo e dos objetos de ensino, uma vez que há a ideia persistente de que cabe ao professor fazer a opção pelas atividades didáticas e pela organização/seleção dos objetos de ensino conforme seu projeto didático autoral de aula. Segundo a Proposta Curricular da CENP - Coordenadoria de Estudos e Normas Pedagógicas de São Paulo - de 1986, por exemplo, cabem ao professor a sequência e o detalhamento dos conteúdos por série. As próprias diretrizes de 1886, conforme Fregonezi (1999, p. 19), destacam que "não há mais uma fixação e sequenciação de programas em nível nacional e que hoje o que se faz é a fixação e sequenciação de objetivos para cada área. Com base nesses objetivos é que se fixam os conteúdos". Tal movimento no âmbito do currículo prescrito é legitimado pelas políticas públicas no fim do século XX.

\section{O PNLD e os PCN: parâmetros para (re)configuração da disciplina}

Finalizaremos nossa discussão com uma breve reflexão sobre o "impacto" das políticas públicas federais mais recentes sobre o ensino de língua materna, a saber: a reformulação do Programa Nacional do Livro Didático (PNLD) e os Parâmetros Curriculares Nacionais (PCN). Ambas são políticas de governo dos anos 90, especialmente da gestão do ex-presidente Fernando Henrique Cardoso, que procuraram dar continuidade a três processos inter-relacionados: (i) avaliação e distribuição do livro didático, no âmbito de uma política pública e linguística de incentivo à leitura; (ii) normatização/legitimação do ensino que acompanha o surgimento de propostas curriculares oficiais que procuram explicitar diretrizes específicas para cada nível de ensino e disciplina escolar; (iii) estabelecimento sistemático de avaliações em rede da educação básica. 
De forma geral, podemos dizer que tanto o PNLD quando a publicação dos PCN dialogam com as ações variadas da Lei de Diretrizes de Bases de Educação Nacional (LDB-96), além de representarem políticas públicas e documentos oficiais em que se procurou "sintetizar" as discussões (algumas consensuais outras nem tanto) sobre o ensino de língua materna ocorridas, entre os anos 70 e 90, tanto na esfera acadêmica quanto nas propostas curriculares estaduais. Nas palavras de Rangel (2001, p. 13), "o que hoje entendemos como ensino de língua materna é, portanto, uma espécie de síntese de respostas possíveis e legítimas aos questionamentos combinados das ciências da aprendizagem e da linguagem ao que convencionou chamar de 'ensino tradicional'". Nesse discurso, os PCN podem ser compreendidos como uma crítica ao dito "ensino tradicional”, apostando em um trabalho com a língua(gem) baseada nas práticas sociais. Na mesma direção, o PNLD assume um caráter de "combate" as "pragas do ensino de português", entendido por alguns como uma política de "educação linguística", distanciando-se, em certo sentido, dos critérios dos professores para escolha de um "bom livro didático" e aproximando cada vez mais do que é legitimado pela ciência como "ideal" para o ensino de língua materna. Desta forma, os PCN têm a função de selecionar e organizar determinados objetivos para a construção de materiais didáticos e programas de ensino, enquanto que o PNLD exerceria uma dupla função: avaliação dessas propostas pedagógicas e legitimação pelos critérios de avaliação de formas de selecionar e organizar os objetos de ensino.

Tanto os PCN quanto os critérios do PNLD se orientam para um currículo prescrito de língua materna que enfoquem práticas de usos da língua(gem) e de reflexão sobre os usos. Ambas as políticas públicas apostam no texto como unidade de ensino e nos gêneros como objetos de ensino. Desta forma, elas reafirmam tendências anteriores ao documento oficial e já conhecidas no cenário acadêmico, tais como o texto como unidade de ensino e/ou a diversidade textual e linguística como destaque para o ensino da língua materna. Por outro lado, outras discussões começam a ser intensificadas através das propostas oficiais, tais como o ensino de gêneros orais e escritos organizados por projetos ou por sequências 
didáticas. De forma geral, Rojo (2000) sintetiza bem a característica geral da proposta curricular dos PCN que se apresenta, a nosso ver, como base também para o PNLD:

as práticas de leitura/escuta de textos e de produção de textos orais e escritos estariam integradas na abordagem do texto como unidade de ensino para a construção do gênero como objeto de ensino e as práticas de análise lingüística ou de reflexão sobre a linguagem seriam resultantes destas e estariam também interligadas nas práticas de uso da linguagem (ROJO, 2000, p. 35).

Em relação ao ensino de língua materna para os $3^{\circ}$ e $4^{\circ}$ ciclos do ensino fundamental, observa-se uma aposta em um ensino voltado para o ensino de práticas sociais e atividades de linguagem específicas: escuta, leitura, produção e análise de textos orais e escritos. Por essa razão, os conteúdos nos PCN encontram-se distribuídos em dois grandes eixos: "Eixo do Uso" e "Eixo da Reflexão". Ao apostar no uso da língua(gem), o documento defende um ensino de língua materna que envolva "a historicidade da linguagem e da língua", "a constituição do contexto de produção", as "implicações do contexto de produção na organização dos discursos e no processo de significação", etc. Nessa perspectiva de ensino-aprendizagem instaurada pelos PCN (1998), o objeto de ensino passa a ser o gênero, não mais os textos, as frases ou as palavras. Além disso, os PCN de LP, segundo determinados critérios de circulação social pública e de menor domínio dos alunos, elegem quatro agrupamentos para um trabalho com crianças e jovens, a saber: literários, de imprensa, publicitário e de divulgação científica. Dessa forma, a disciplina assume uma perspectiva de um trabalho com a língua em uso nos diferentes gêneros e textos que circulam na sociedade contemporânea, afastando-se de uma visão reducionista de língua(gem) e da perspectiva técnica ou comunicativa dos anos 70 e 80 . Um efeito visível de tal movimento curricular pode ser visto nas recentes coleções aprovadas no âmbito do PNLD, nas reportagens de revistas pedagógicas voltadas para a docência, assim como programas específicos do Ministério da Educação, tais 
como o PNBE (Plano Nacional da Biblioteca Escolar) e as Olimpíadas da Língua Portuguesa.

\section{Considerações finais}

Se essas análises em termos macroscópicos trazem vários elementos para compreensão de determinadas facetas da disciplina escolar e do processo de ensino-aprendizagem, elas ainda informam pouco sobre os funcionamentos internos da escola e sobre as práticas cotidianas de ensino. Apesar do risco de incorrer em simplificações e generalizações, o presente trabalho revela que a disciplina escolar vai se reconfigurando nas práticas escolares em diálogo com as políticas públicas para a educação e, mais recentemente, com as pesquisas acadêmicas sobre ensino de língua nas escolas.

Nossas reflexões sugerem também um deslocamento de uma perspectiva analítica que vê os saberes escolares como algo abstrato e genérico, depositado na memória de professores e alunos. Acreditamos, como Signorini (2006, p. 187), que tais saberes passam a "ter a consistência dos modos de raciocionar/agir/avaliar tanto gerados quanto instanciados, tranformados e/ou subvertidos pelas ações, retroações, bifurcações que dão corpo e visibilidade às práticas escolares". Nossa tentativa de fazer uma interpretação que enfocasse algumas facetas dessa complexa dinâmica discursiva mostrou a necessidade de estudos no campo aplicado que se voltem para esse terreno complexo de negociação, de intercalações, de sedimentações, de dúvidas e de riscos. No caso do ensino de língua materna, alguns processos tornam-se fundamentais e necessitam de pesquisas de caráter histórico, tais como: as políticas linguísticas, o processo de gramaticalização, as relações entre o português europeu e o português brasileiro, a nacionalização do ensino com destaque para o trabalho com a língua e a literatura nacional, as políticas públicas voltadas para educação linguística e as pesquisas sobre o ensino de língua materna. As alterações nos nomes da disciplina (Gramática Nacional, Português, Comunicação \& Expressão em Língua Portuguesa) e o processo contínuo de (re)construção dos objetos de 
ensino demonstram claramente que fabricamos uma disciplina escolar em que o foco seja a língua portuguesa falada e escrita no Brasil com tempos, espaços, práticas e impressos específicos. Um movimento complexo e cheio de tensões, permanências e rupturas com metadiscursos sobre a língua e sua função na sociedade e na escola, como bem demonstra o poema "Aula de Português", de Carlos Drummond de Andrade:

\author{
A linguagem \\ na ponta da língua, \\ tão fácil de falar \\ e de entender.
}

A linguagem

na superfície estrelada de letras, sabe lá o que ela quer dizer?

Professor Carlos Góis, ele é quem sabe, e vai desmatando o amazonas de minha ignorância.

Figuras de gramática, esquipáticas, atropolem-me, aturdem-me, sequestram-me.

Já esqueci a língua em que comia, em que pedia para ir lá fora, em que levava e dava pontapé a língua, breve língua entercortada do namoro com a prima.

O português são dois, o outro, mistério.

\title{
Referências
}

ANGELO, G. Revisitando o ensino tradicional de língua portuguesa. 2005. 265 f. Tese (doutorado em Linguística Aplicada) - Universidade de Campinas, Campinas, 2005. 
AUROUX, S. A revolução tecnológica da gramaticalização. Campinas: Ed. da Unicamp, 1992.

BAGNO, M. Língua, história e sociedade. In: BAGNO, M. (Org.). Linguística da norma. São Paulo: Loyola, 2002.

BATISTA, A. A. G. Aula de português: discurso e saberes escolares. São Paulo: M. Fontes, 1997.

BOTO, C. Aprender a ler entre cartilhas: civilidade, civilização e civismo pelas lentes do livro didático. In: Educação e Pesquisa, São Paulo, v. 30 n. 3, p. 493511, set./dez. 2004.

BUNZEN, C. Dinâmicas discursivas na aula de português: os usos do livro didático e projeto didáticos autorais. 2009. 227 f. Tese (Doutorado em Linguistica Aplicada) - Universidade Estadual de Campinas, Campinas, 2009.

CASAGRANDE, N. dos S.; BASTOS, N. M. O. B. Ensino de língua portuguesa e políticas lingüísticas: século XVI e XVII. In: BASTOS, N. M. O. B. (Org.). Língua portuguesa: uma visão em mosaico. São Paulo: EDUC/PUC-SP, 2002.

CHERVEL, A. História das disciplinas escolares: reflexões sobre um campo de pesquisa. In: Teoria e Educação, Porto Alegre, n. 2, p. 177-229, 1990.

DIONISIO, M. de L. A construção escolar de comunidades de leitores. Coimbra: Livraria Almedina, 2000.

FACCINA, R. Políticas linguísticas e ensino de língua portuguesa: da República Velha à Constituição de 1934. 2000. Disponível em: <http://www.mackenzie.br/fileadmin/Pos_Graduacao/Doutorado/Letras/Publicacoes/Artigo_ RoseFaccina_PoliticasLinguisticaseEnsinoLP.pdf >. Acesso em: 12 mar. 2007.

FARACO, C. A. As sete pragas do ensino de português. In: GERALDI, J. W. (Org.). O texto na sala de aula: leitura \& produção. 3. ed. Cascavel: ASOESTE, 1984.

FARACO, C. A. Por uma pedagogia da variação lingüística. In: CORREA, D. A. (Org.). A relevância social da linguística: linguagem, teoria e ensino. São Paulo: Parábola Editorial; Ponta Grossa: Editora da UEPG, 2007. 
FREGONEZI, E. Conteúdo programático de Língua Portuguesa. In: FREGONEZI, E. Elementos de ensino de língua portuguesa. São Paulo: Arte e Ciência, 1999.

GERALDI, J. W.; SILVA, L.; FIAD, R. Lingüística, ensino de língua materna e formação de professores. In: DELTA, v. 12, n. 2, p. 307-326, 1996.

GUIMARÃES, E. Multilinguismo: divisões da língua e ensino no Brasil. Campinas: CEFIEL/IEL, 2005.

HAIDAR, M. de L. M. O ensino secundário no Império Brasileiro. São Paulo: Edusp, 1972.

HILSDORF, M. L. S. História da educação brasileira: leituras. 2. ed. São Paulo: Pioneira Thomson Learning, 2005.

ILARI, R.; BASSO, R. O português da gente: a língua que estudamos, a língua que falamos. São Paulo: Contexto, 2006.

LAURIA, M. P. Livro didático de português: entre as concepções de ensino, trilhos da lei e as sendas do texto. 2004. 425 f. Tese (Doutorado em Educação) Faculdade de Educação da Universidade de São Paulo, São Paulo, 2004.

MARINHO, M. Discursos sobre a língua nos currículos de final do século. In: BARRETO, E. S. S. et al. Os currículos do ensino fundamental para as escolas brasileiras. Campinas: Autores Associados; São Paulo: Fundação Carlos Chagas, 1998.

PFROMM NETO, S.; et al. O livro na Educação. Rio de Janeiro: Primor/Instituto Nacional do Livro, 1974.

PIETRI, E. de. A constituição do discurso da mudança no ensino de língua portuguesa. 2003. Tese (Doutorado em Lingüística Aplicada) - Universidade Estadual de Campinas, Campinas, 2003.

RANGEL, E. Livro didático de língua portuguesa: o retorno do recalcado. In: DIONÍSIO, A.; BEZERRA, M. A. (Org.). O livro didático de Português: múltiplos olhares. Rio de Janeiro: Lucerna, 2001. 
RAZZINI, M. de P. G. 0 espelho da nação: a Antologia Nacional e o ensino de português e de literatura. 2000. Tese (Doutorado) - Universidade Estadual de Campinas, Campinas, 2000.

ROJO, R. Modos de transposição didática dos PCNs às práticas de sala de aula: progressão curricular e projetos. In: Rojo, R. (Org.). A prática de linguagem em sala de aula: praticando os PCNs. São Paulo: EDUC; Campinas: Mercado de Letras, 2000.

ROJO, R; CORDEIRO, G. S. Apresentação: gêneros orais e escritos como objetos de ensino: modo de pensar, modo de fazer. In: SCHNEUWLY, B; DOLZ, J. (Org.). Gêneros orais e escritos na escola. Campinas: Mercado de Letras, 2004.

ROJO, R. Gêneros de discurso/texto como objeto de ensino de línguas: retorno ao trivium? In: SIGNORINI, I. (Org.). [Re]discutir texto, gênero e discurso. São Paulo: Parábola Editorial, 2008.

SIGNORINI, I. A questão da língua legítima na sociedade democrática: um desafio para a linguística aplicada contemporânea. In: LOPES, L. P. da M. (Org.). Por uma linguística aplicada indisciplinar. São Paulo: Parábola Editorial, 2006.

SOARES, M. Português na escola: história de uma disciplina curricular. In: BAGNO, M. (Org.). Linguística da norma. São Paulo: Loyola, 2002.

ZILBERMAN, R. No começo, a leitura. Em Aberto, Brasília, n. 69, ano 16, 1996. ZOTTI, S. Sociedade, educação e currículo no Brasil: dos jesuítas aos anos de 1980. Campinas: Autores Associados, 2004.

Recebido: 27/06/2011

Received: 06/27/2011

Aprovado: 22/08/2011

Approved: 08/22/2011 